\title{
On Seeing Our Deepest Intellectual, Educational and Practical Traditions from a Non-Western Perspective
}

\author{
Ian Winchester
}

Published online: 16 March 2013

(C) Springer Science+Business Media Dordrecht 2013

In journals like Interchange and in countries like Canada, the United States, France, Germany, Italy, Scandinavia, the Netherlands, or the United Kingdom we tend to trace out intellectual beginnings and our academic approaches to the Greeks. This means essentially the ways and thoughts of Pythagoras, Archimedes, Homer, Aeschylus, Euripides, Socrates, Plato, Aristotle, Herodotus, Thucydides, and a host of lesser lights still shine brightly for us and are the official beginning of the traditions to which we still hold. Thus our sense of the literary, of plays, poetry, of history, of philosophy, of mathematics, physics, and the sciences are all determined if not exhausted by Greek models carried on to us via the Romans and later the Christian church centred in Rome or its Greek Orthodox counterpart in Athens. The papers in this journal still tend to follow the academic writing pattern of Aristotle, the scholarly, professorial pattern. The logic is the logic of Aristotle. The rhetorical forms are the rhetorical forms we can see in Plato's characterization of Socrates' arguments with the great men of his day. We tend to take these sorts of things as true and see Greece as the origin of practically all our intellectual traditions and see the traditions of others as either feeble in comparison or indeed not really existent. In their article Sriraman and Benesh challenge this. Although they do not quite put it this way, they see Western science as essentially a third person, common object tradition whereas Indian or Vedic tradition is essentially a first person tradition or science aimed at nature as object as compared to science aimed at mind as subject. The Dalai Lama has written in a similar vein from a Buddhist perspective.

It is hard for us to imagine that there are other intellectual traditions and other ways than our own and even when we acknowledge them it is equally hard for us to see any particular merit in them. Yet the Chinese, the peoples of India and indeed our own aboriginal peoples have their own traditions and ways of great historical,

\footnotetext{
I. Winchester $(\bowtie)$

Faculty of Education, University of Calgary,

2500 University Drive N.W., Calgary, AB T2N 1N4, Canada

e-mail: winchest@ucalgary.ca
} 
intellectual, and practical merit. The Chinese and the peoples of India can lay claim to having longer-standing intellectual traditions and ways than our own. The Inuit can claim to have survived for millennia in what is perhaps the most inhospitable conditions for human life on the planet and been remarkably creative about it. They could not have done that without traditions comparable to our European "sciences" that were sufficient for their survival. Undoubtedly the Chinese and the Indians have in recent times learned from the intellectual traditions of Europe and North America and their success at embracing them had put them poised in the long run to surpass us even in material terms. But they have their own intellectual and practical traditions of great antiquity and power.

The Inuit, though small in number, have shown a remarkable capacity to embrace modern technologies with astonishing ease. Due to his Royal Canadian Airforce duties my father worked for a time at the busiest airport during the Second World War, Gander airport in Newfoundland, where many Inuit were employed as aircraft mechanics. One of the most astonishing experiences of his life was watching Inuit men acting as the very best aircraft mechanics maintaining Allied planes though they could not read or write English and could not consult the manuals, yet they had a natural grasp of mechanical things from their own experience in making the necessary tools for survival in the Arctic from stone, bone, fine coordination and intelligence. Their own "sciences" and the things they learned from them were sufficient unto the day. That is an important lesson that I have held all my adult life.

The papers in this issue of Interchange are all somewhat unusual for a reader of standard Western journal fare. We do not usually offer papers that discuss non-dual perspectives as Western thought usually involves dualisms: dark/light; night/day; large/small; hot/cold; mind/matter; thought/action; love/hate; god/devil; good/evil, and so on and on. For curriculum if it is anything, we might think, is a Western notion and so needs no rethinking or translating. Sriraman and Benesh do us the service in their article of challenging out dualistic assumptions and offer us other ways of looking at the world derived from the Indian philosophical tradition.

Nor do we often think of a curriculum from the perspective of the "Eskimo" as we used until recently to refer in English to the people who refer to themselves as "the people" or Inuit. McMillan offers us, in her paper describing a new approach to Inuit science education in the Canadian territory of Nunavut, the results of a multiyear research project that helps us better to understand how we might have two way learning in developing lessons in science that depend in part on Inuit legends and oral histories.

We take it for granted in our time that a classroom ought to be a beehive of activity on the part of students. This may well be due initially to the influence of Maria Montessori who demonstrated that the children under her care in Italy, thought to be unteachable as they were parentless street urchins, could indeed learn as well or better than the children who were raised in normal homes and went to normal schools provided only that they had a chance to be active with suitable materials in their own learning and were not required to sit passively and memorize. But Lee and her co-author show us how a pedagogy of silence can work in a Korean mathematics education context and offer us a theory of why and how this actually 
works, contrary to present western assumptions, expectations, and pedagogical theories.

Finally, two Chinese authors, Liang and Han attempt to tell us about their comparative understanding of higher education in China and Canada from what they term the perspective of a "humanity orientation". By this they mean an emphasis on the understanding of individual human emotions, respect for the individual generally, the concern to inspire a sense of responsibility, self-awareness, initiative and creativity as ideals for the products of higher education. Readers from a Canadian perspective will find the commentary on the Chinese system interesting and different in many ways, as will Chinese readers who discover something about the Canadian system for the first time in these pages. It is fascinating to see what is so familiar through the eyes of others who see our ways as odd and different. For example, our authors notice that Canadian libraries often have special provisions for the disabled and the movement hindered or otherwise handicapped students, something that is rare or non-existent in China. I have made it a point not to edit into the standard expression of this journal the sometimes unusual expressions of Liang and Han as they seem to me to be making their points from a different vantage point and their expression is part of that vantage point.

We hope that our readers will enjoy this different and important fare as much as we have and will ponder its implications, perhaps writing in "interchange" with the authors.

Ian Winchester

Editor 